\title{
Aplicação de 1-metilciclopropeno, estresse inicial com baixo oxigênio e armazenamento em ultrabaixo oxigênio na qualidade de maçã Fuji
}

\author{
Application of 1-methylcyclopropene, initial low oxygen stress and storage in ultralow oxygen on Fuji \\ apples quality
}

\author{
Auri Brackmann I Adriano Roque de Gasperin ${ }^{\mathrm{II}}$ Vanderlei Both" Elizandra Pivotto Pavanello ${ }^{\mathrm{III}}$ \\ Márcio Renan Weber SchorriII Rogério de Oliveira Anese ${ }^{\mathrm{III}}$
}

\section{RESUMO}

O objetivo deste trabalho foi avaliar o efeito da aplicação de 1-MCP em combinação com condições de estresse inicial com baixo $\mathrm{O}_{2}$ e armazenamento em atmosfera controlada com pressões parciais ultrabaixas de $\mathrm{O}_{2}$ sobre a manutenção da qualidade de maçãs Fuji. Os tratamentos avaliados foram com e sem aplicação de 1-MCP (1.000nL $\left.L^{-1}\right)$, combinado com cinco níveis do fator condição de armazenamento (sem estresse inicial $+0,6 \mathrm{kPa} \mathrm{O}_{2}, 1$ estresse $+0,6 \mathrm{kPa} \mathrm{O}_{2}, 1$ estresse $+0,8 \mathrm{kPa} \mathrm{O}_{2}, 2$ estresses $+0,6 \mathrm{kPa} \mathrm{O}_{2}$ e sem estresse inicial + $1,0 \mathrm{kPa} \mathrm{O}_{2}$ ). Cada estresse inicial foi com $0,2 \mathrm{kPa}$ de $\mathrm{O}_{2}$ pelo período de 14 dias. Os frutos foram armazenados nessas condições durante oito meses a $-0,5^{\circ} \mathrm{C} \pm 0,2^{\circ} \mathrm{C}$ e UR de $96 \pm 1 \%$, mais sete dias de exposição a $20 \pm 1^{\circ} \mathrm{C}$. Em todos os tratamentos, o $\mathrm{CO}_{2}$ foi mantido abaixo de $0,5 \mathrm{kPa}$. $\mathrm{O}$ armazenamento sem estresse inicial por baixo $\mathrm{O}_{2}$ associado a $1,0 \mathrm{kPa}$ ou $0,6 \mathrm{kPa}$ de $\mathrm{O}_{2}$ manteve a polpa mais firme e com maior acidez titulável. Além disso, proporcionou menor ocorrência de podridão após oito meses de armazenamento mais sete dias a $20^{\circ} \mathrm{C}$. O 1-MCP proporcionou menor atividade da enzima ACC oxidase, no entanto, não foi eficiente para a redução da produção de etileno e para retardar a perda da firmeza e a ocorrência de podridão. $\mathrm{O}$ estresse inicial de 14 dias com $0,2 \mathrm{kPa}$ de $\mathrm{O}_{2}$ prejudicou a conservação de maçãs Fuji.

Palavras-chave: Malus domestica, pós-colheita, atmosfera controlada, qualidade.

\section{ABSTRACT}

The aim of this research was to evaluate the effect of 1-MCP application in combination with initial low oxygen stress and storage in controlled atmosphere with ultra-low oxygen on Fuji apple quality preservation. The evaluated treatments consisted of 1-MCP application (with or without $\left.1000 \mathrm{~nL} \mathrm{~L}^{-1}\right)$ combined with five levels of the factor storage condition (without initial stress $+0.6 \mathrm{kPa} \mathrm{O}_{2}, 1$ stress $+0.6 \mathrm{kPa}$ $\mathrm{O}_{2}, 1$ stress $+0.8 \mathrm{kPaO} \mathrm{O}_{2}, 2$ stresses $+0.6 \mathrm{kPaO} \mathrm{O}_{2}$ and without initial stress $+1.0 \mathrm{kPa} \mathrm{O}_{2}$ ). Initial low oxygen stress was applied by 14 days at $0.2 \mathrm{kPa} \mathrm{O}_{2}$. The fruits were stored in these conditions for eight months at $-0.5 \pm 0.2^{\circ} \mathrm{C}$ and relative humidity of $96 \pm 1 \%$, followed by seven days at $20 \pm 1^{\circ} \mathrm{C}$. In all treatments, the $\mathrm{CO}_{2}$ was kept below $0.5 \mathrm{kPa}$. The storage without initial low oxygen stress associated with $1.0 \mathrm{kPa}$ or $0.6 \mathrm{kPa} \mathrm{O}_{2}$ maintained the pulp firmer and with the higher titratable acidity, moreover provided a lower incidence of decay after storage during eight months and shelf life at $20^{\circ} \mathrm{C}$. The $1-\mathrm{MCP}$ provided lower activity of ACC oxidase enzyme, however, did not reduces ethylene production and failed to delay the loss of firmness and the control decay. Initial stress of 14 days with $0.2 \mathrm{kPa} \mathrm{O}_{2}$ reduced the conservation of Fuji apples.

Key words: Malus domestica, postharvest, Controlled atmosphere, quality.

\section{INTRODUÇÃO}

No Brasil, a atmosfera controlada (AC) é atualmente a técnica de armazenamento mais utilizada para o armazenamento de maçãs. No caso da cultivar 'Fuji', os maiores problemas que ocorrem durante o armazenamento estão relacionados com a sua suscetibilidade ao alto $\mathrm{CO}_{2}$ quando armazenada em condição de AC (ARGENTA et al., 2002), sendo também mais suscetível à ocorrência de podridões pós-colheita que outras cultivares (VALDEBENITO SANHUEZA et al., 2006). Sendo assim, mesmo em condições de AC,

\footnotetext{
IDepartamento de Fitotecnia, Universidade Federal de Santa Maria (UFSM), 97105-900, Santa Maria, RS, Brasil. E-mail: auribrackmann@gmail.com. Autor para correspondência.

${ }^{\text {IIC }}$ urso de Agronomia, UFSM, Santa Maria, RS, Brasil.

IIIPrograma de Pós-graduação em Agronomia (PPGA), UFSM, Santa Maria, RS, Brasil.
} 
ocorrem perdas durante o armazenamento dessa cultivar. Dessa forma, as pesquisas buscam alternativas adicionais viáveis para serem aplicadas em nível comercial para manter a qualidade da fruta por longos períodos. Dentre as técnicas auxiliares no armazenamento em AC, está a aplicação de 1-MCP (1metilciclopropeno), a indução inicial de estresse com baixo $\mathrm{O}_{2}$ (ILOS - Initial low oxygen stress) e o armazenamento em pressões parciais ultrabaixas de $\mathrm{O}_{2}$ (ULO - Ultra Low Oxygen).

A aplicação de 1-MCP tem efeito maior em $\mathrm{AC}$ do que no armazenamento refrigerado (WATKINS et al., 2000). O 1-MCP inibe a ação do etileno, reduzindo a velocidade de maturação e de senescência de maçãs (WATKINS et al., 2000), reduz substancialmente a perda de firmeza (BLANKENSHIP \& UNRATH, 1998), mantém a acidez titulável e sólidos solúveis (ZANELLA, 2003), reduz a respiração e a produção de etileno (FAN et al., 1999).

Além da aplicação do 1-MCP, o armazenamento em AC com o uso de baixos níveis de oxigênio é uma técnica que pode resultar na manutenção da qualidade dos frutos. Entretanto, o armazenamento nessas condições por um período prolongado proporciona risco de ocorrência de distúrbios fisiológicos, como o desenvolvimento de degenerescência da polpa (BRACKMANN et al., 2002). $\mathrm{O}$ uso do estresse inicial pela exposição dos frutos a condições de baixo $\mathrm{O}_{2}\left(0,2\right.$ a $0,3 \mathrm{kPa}$ de $\left.\mathrm{O}_{2}\right)$, antes do armazenamento em $\mathrm{AC}$, causa um estresse fermentativo (respiração anaeróbica) inicial no fruto. Durante o período de estresse, ocorre um aumento na produção de etanol nos frutos, que, em níveis baixos, reduz a ocorrência de escaldadura (WANG \& DILLEY, 2000; ZANELLA, 2003) e também age como regulador da transcrição de genes da rota de biossíntese do etileno (ASODA et al., 2009).

No entanto, no Brasil, algumas técnicas adicionais ao armazenamento em $\mathrm{AC}$ ainda não estão bem elucidadas, já que podem ocorrer variações entre os diferentes locais de cultivo. As pressões parciais ultrabaixas de $\mathrm{O}_{2}$, por exemplo, variam com a cultivar, temperatura e duração de armazenamento (CERETTAet al., 2010). Tanto o estresse inicial com baixo $\mathrm{O}_{2}$ quanto as pressões ultrabaixas de $\mathrm{O}_{2}$ são técnicas que não necessitam de produtos químicos. ILOS seguido do armazenamento em $1,5 \mathrm{kPa}$ de $\mathrm{O}_{2}$ proporciona completo controle da escaldadura de maçãs Granny Smith e Law Rome, evitando o uso do antioxidante difenilamina e fungicidas pós-colheita(WANG \& DILLEY, 2000). Além disso, essas técnicas são de baixo custo, uma vez que fazem uso dos mesmos equipamentos utilizados para armazenamento em $\mathrm{AC}$, não necessitando de novas aquisições.
Dessa forma, o objetivo deste trabalho foi avaliar o efeito da aplicação de 1-MCP em combinação com condições de estresse inicial com baixo $\mathrm{O}_{2}$ seguido do armazenamento em pressões parciais ultrabaixas de $\mathrm{O}_{2}$ na manutenção da qualidade de maçã Fuji.

\section{MATERIAL E MÉTODOS}

Os frutos da cultivar 'Fuji' foram colhidos num pomar comercial localizado em Vacaria, RS. Antes da aplicação dos tratamentos, procedeu-se uma seleção, eliminando os frutos com lesões e/ou defeitos e, posteriormente, homogeneizando as unidades experimentais. Estas foram compostas por 25 frutos.

O delineamento experimental utilizado foi o inteiramente casualizado, arranjado em esquema bifatorial, com quatro repetições. Os dez tratamentos originaram-se da combinação de dois níveis do fator 1MCP (com ou sem 1.000 $\mathrm{nL} \mathrm{L}^{-1}$ ) com cinco níveis do fator condição de armazenamento (sem estresse inicial $+0,6 \mathrm{kPa} \mathrm{O}, 1$ estresse $+0,6 \mathrm{kPa} \mathrm{O}_{2}, 1$ estresse $+0,8 \mathrm{kPa}$ $\mathrm{O}_{2}, 2$ estresses $+0,6 \mathrm{kPa} \mathrm{O}_{2}$ e sem estresse inicial + $1,0 \mathrm{kPa} \mathrm{O}_{2}$ ). Todos os tratamentos foram mantidos com nível de $\mathrm{CO}_{2}$ abaixo de $0,5 \mathrm{kPa}$. Acrescenta-se que a pressão de $1,0 \mathrm{kPa} \mathrm{O}_{2}$ é o padrão praticado nas câmaras de armazenamento de maçã Fuji.

Para a aplicação do estresse, os frutos foram armazenados em minicâmaras onde permaneceram por um período de 14 dias numa atmosfera com $0,2 \mathrm{kPa}$ de $\mathrm{O}_{2}$ e $0,0 \mathrm{kPa}$ de $\mathrm{CO}_{2}$. No tratamento com dois estresses, após o primeiro, os frutos permaneceram por cinco dias na condição de $0,6 \mathrm{kPa}$ de $\mathrm{O}_{2}$ e $0,0 \mathrm{kPa}$ de $\mathrm{CO}_{2}$ antes de receber o segundo. Após o estresse, os frutos permaneceram nas condições de AC descritas acima.

Os frutos foram armazenados durante oito meses em minicâmaras experimentais herméticas, com volume de $0,232 \mathrm{~m}^{3}$, as quais foram conectadas por tubulações plásticas a uma mesa de controle com analisadores de gases. As minicâmaras permaneceram no interior de uma câmara frigorífica com a temperatura de $-0,5 \pm 0,2^{\circ} \mathrm{C}$. A umidade relativa no interior das minicâmaras foi mantida em $96 \pm 1 \%$.

O produto 1-MCP foi aplicado antes do armazenamento em AC. Como fonte de 1-MCP foi utilizado o produto SmartFresh ${ }^{\circledR}$ (Rohm \&HassCo) na concentração de $1.000 \mathrm{~nL} \mathrm{~L}^{-1}$, estando dentro da faixa testada por CORRENT et al. (2005) para a maçã Fuji. O produto foi solubilizado em $25 \mathrm{~mL}$ de água em um recipiente hermético e, posteriormente, a solução foi transferida para uma placa de petri, já no interior da minicâmara, que foi imediatamente fechada permanecendo assim durante 24 horas, na temperatura de armazenamento. Em seguida, as minicâmaras foram ventiladas com auxílio de uma bomba de sucção. 
Para os tratamentos com estresse inicial por baixo $\mathrm{O}_{2}$ e o estabelecimento de $\mathrm{AC}$, as pressões parciais de $\mathrm{O}_{2}$ foram obtidas por diluição do $\mathrm{O}_{2}$ do ar, por meio da injeção de $\mathrm{N}_{2}$ nas minicâmaras. Durante todo o período de armazenamento, houve monitoramento diário das concentrações dos gases, sendo que o $\mathrm{O}_{2}$ consumido pela respiração foi reposto através da injeção de ar atmosférico nas minicâmaras. $\mathrm{O} \mathrm{CO}_{2}$ produzido pelos frutos foi eliminado por reação química com hidróxido do cálcio (cal hidratada) colocado no interior das minicâmaras, de modo que permaneceu abaixo de $0,5 \mathrm{kPa}$ durante todo período de armazenamento.

As análises da qualidade dos frutos foram realizadas após oito meses de armazenamento mais sete dias de exposição a $20 \pm 1^{\circ} \mathrm{C}$ (UR $82 \pm 5 \%$ ), para simular o período de comercialização. As variáveis avaliadas foram: a) Podridões: determinada pela contagem de frutos que apresentavam lesões de diâmetro maior que $0,5 \mathrm{~cm}$ e características típicas de ataque por patógenos; b) Firmeza de polpa: determinada com o uso de um penetrômetro com ponteira de $11 \mathrm{~mm}$, inserido em dois lados opostos da região equatorial do fruto, onde foi retirada previamente a epiderme; c) Degenerescência da polpa: determinada através do número de frutos, que, submetidos a vários cortes transversais, apresentavam manchas escurecidas na polpa; d) Frutos sadios: frutos sem ocorrência de podridão, degenerescência da polpa e/ou outros danos que impossibilitam a sua comercialização; e) Acidez titulável: utilizou-se $10 \mathrm{~mL}$ de suco que foram diluídos em $100 \mathrm{~mL}$ de água destilada e titulados com uma solução de hidróxido de sódio $0,1 \mathrm{~N}$ até $\mathrm{pH} 8,1$ sendo expressa em meq $100 \mathrm{~mL}^{-1}$; f) Sólidos solúveis totais (SST): realizada com refratômetro manual e a leitura corrigida em função do efeito da temperatura e expresso em ${ }^{\circ}$ Brix; g) Atividade da ACC oxidase: de acordo com a metodologia proposta por BUFLER (1986); h) Produção de etileno: detectado por um cromatógrafo a gás, marca Varian ${ }^{\circledR}$ modelo Star 3400CX. Como fase estacionária, foi usada uma coluna empacotada com Porapak $\mathrm{N}$ de 2,0m de comprimento e tendo como fase móvel o Nitrogênio. As temperaturas empregadas foram $90^{\circ} \mathrm{C}$, $140^{\circ} \mathrm{C}$ e $200^{\circ} \mathrm{C}$ para coluna, injetor e detector, respectivamente. A partir de uma massa conhecida de frutos, acondicionada em recipientes de vidro com volume de $5 \mathrm{~L}$ hermeticamente vedados por um período de tempo conhecido, retirou-se uma amostra de $1 \mathrm{~mL}$ do headspace de cada recipiente, que foi posteriormente injetado no cromatógrafo. Os valores médios foram obtidos em ppm e posteriormente convertidos e expressos em $\mu \mathrm{L} \mathrm{C}{ }_{2} \mathrm{H}_{4}$ $\mathrm{kg}^{-1} \mathrm{~h}^{-1}$; i) Respiração: quantidade produzida de $\mathrm{CO}_{2}$ pelos frutos dos mesmos recipientes utilizados para determinação de etileno, que foi circulado por um analisador de gases marca Agri-datalog e expressa em $\mathrm{mL} \mathrm{CO}_{2} \mathrm{~kg}^{-1} \mathrm{~h}^{-1}$, em função da massa de frutos, do volume livre do recipiente, do tempo de fechamento e da concentração de $\mathrm{CO}_{2}$ presente nos recipientes.

$\mathrm{Na}$ análise estatística, os dados expressos em porcentagem foram transformados pela fórmula arc.sen $\sqrt{(x+0,5) / 100}$, antes de realizar a análise de variância. As médias foram comparadas entre si pelo teste de Tukey, em nível de 5\% de probabilidade de erro.

\section{RESULTADOS E DISCUSSÃO}

A ocorrência de podridões nas maçãs, logo após a abertura da câmara, não apresentou diferença significativa entre as condições de armazenamento, bem como para as condições com ou sem 1-MCP (Tabela 1). Já aos sete dias a $20^{\circ} \mathrm{C}$, a incidência de podridões foi menor nos frutos sem 1-MCP que não sofreram estresse inicial por baixo $\mathrm{O}_{2}$ e armazenados em $1,0 \mathrm{kPa}$ de $\mathrm{O}_{2}$. Os frutos tratados com 1-MCP submetidos a dois estresses e posterior armazenamento com $0,6 \mathrm{kPa}$ de $\mathrm{O}_{2}$ apresentaram menor podridão quando comparados com os não tratados com 1-MCP. Somente nesta condição extrema é que a aplicação de 1-MCP apresentou vantagem no controle de podridões. Essa baixa eficiência do 1-MCP pode estar relacionada a um estádio de maturação mais avançado na colheita, que pode ser observado pela baixa firmeza de polpa $(78,2 \mathrm{~N})$, quando comparado com outros trabalhos, a exemplo de CORRENT et al. (2005), que armazenaram maçãs Fuji com 89,6N. ARGENTA et al. (2005) afirmam que o potencial de armazenamento por longos períodos de maçã colhida tardiamente é menor, mesmo com aplicação de 1-MCP. Por outro lado, CORRENT et al. (2005) também verificaram que a aplicação de 1-MCP em maçã Fuji armazenada em AC não trouxe vantagens, sugerindo que as condições de $\mathrm{AC}$ já equivalem à inibição da ação do etileno proporcionado pelo 1-MCP. No entanto, as condições de ULO utilizadas no presente trabalho $\left(0,6 \mathrm{kPa}\right.$ e $0,8 \mathrm{kPa}$ de $\left.\mathrm{O}_{2}\right)$, associadas ao uso de estresse inicial, podem ter induzido a via anaeróbica para fornecer energia aos frutos, na forma de ATP (fosforilação em nível de substrato) (KE et al., 1993), em função das concentrações excessivamente baixas de $\mathrm{O}_{2}$. Quando a respiração anaeróbica for excessiva, é possível o surgimento de danos às células em função do acúmulo de produtos da fermentação, o que facilita infecções patológicas (KADER, 2002).

A aplicação de 1-MCP não interferiu na perda de firmeza de polpa dos frutos, sendo que não houve diferença significativa entre frutos tratados ou não com 1-MCP (Tabela 1). Esses resultados estão de acordo 
Tabela 1 - Ocorrência de podridão, firmeza de polpa e percentagem de frutos sadios em maçãs Fuji após oito meses de armazenamento a $0,5 \pm 0,2^{\circ} \mathrm{C}$ (UR $96 \pm 1 \%$ ) e em atmosfera controlada com ultrabaixo oxigênio e estresse inicial por baixo oxigênio com e sem a aplicação de 1 -MCP $\left(1.000 \mathrm{~nL} \mathrm{~L}^{-1}\right)$, mais sete dias a $20 \pm 1^{\circ} \mathrm{C}(\mathrm{UR} 82 \pm 5 \%)$.

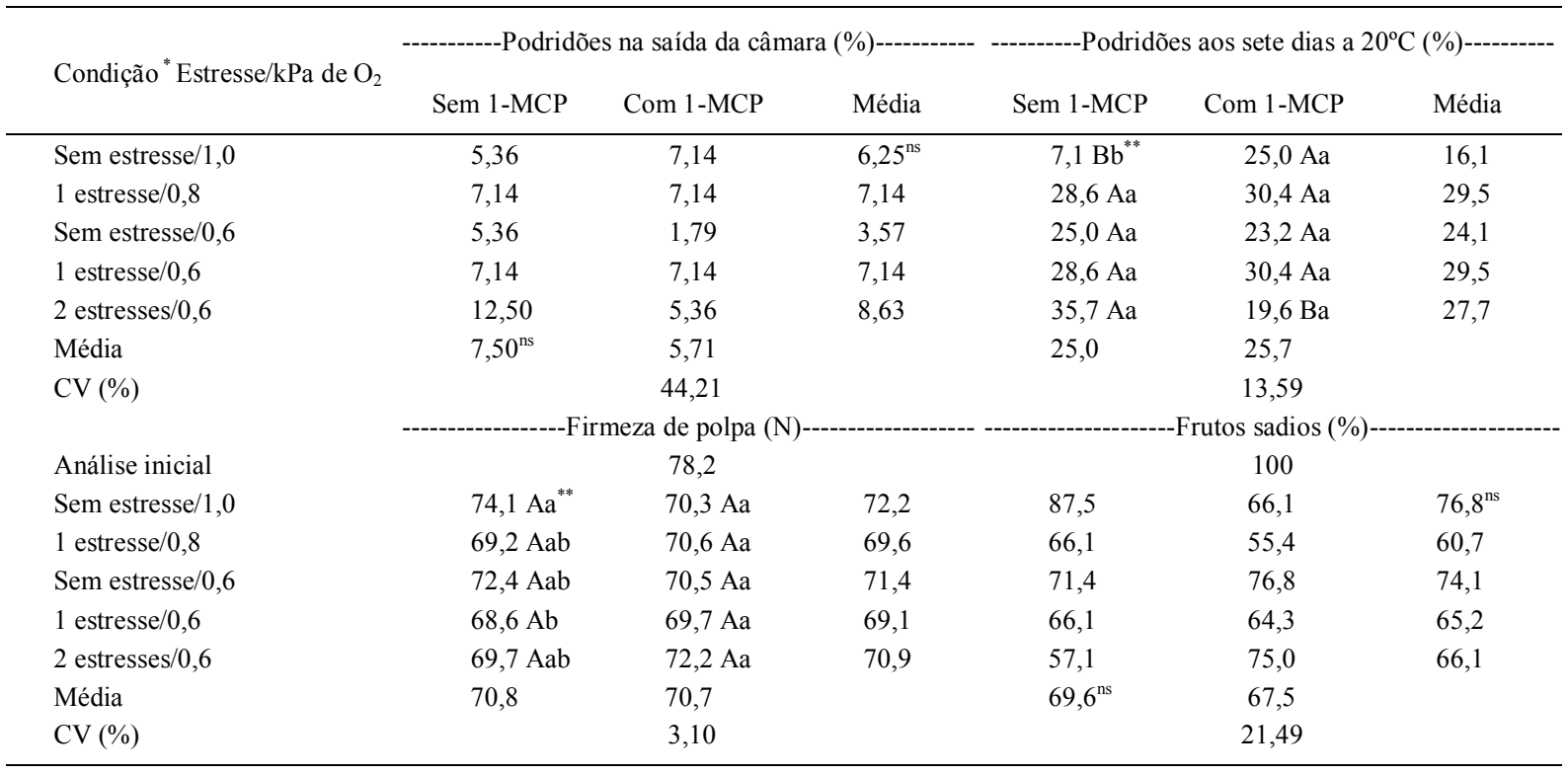

*Estresse inicial por baixo oxigênio obtido por meio da exposição dos frutos durante 14 dias a uma concentração de $0,2 \mathrm{kPa}$ de $\mathrm{O}_{2}$.

${ }^{* *}$ Médias seguidas por letras iguais, maiúsculas nas linhas e minúsculas nas colunas, não diferem entre si pelo teste de Tukey, a 5\% de probabilidade de erro.

${ }^{n s}$ Não significativo.

com CORRENT et al. (2005), que observaram, para esta mesma cultivar armazenada em AC, que tanto as doses de 625 quanto de $1.250 \mathrm{~nL} \mathrm{~L}^{-1}$ de 1 -MCP não foram eficientes em manter a firmeza de polpa dos frutos mais elevada, quando comparada aos frutos não tratados. Provavelmente, as baixas concentrações de $\mathrm{O}_{2}$ utilizadas no presente trabalho, que proporcionaram baixa produção de etileno nos frutos, tenham sido eficientes em manter a firmeza dos frutos de maneira similar aos que receberam 1-MCP, mascarando o efeito do produto nesta cultivar e nestas condições de AC.

Para os frutos que não receberam aplicação de 1-MCP, a manutenção da firmeza após oito meses de armazenamento mais sete dias a $20^{\circ} \mathrm{C}$ foi maior naqueles que não receberam estresse inicial com baixo $\mathrm{O}_{2}$ e permaneceram armazenados em $1,0 \mathrm{kPa}$ de $\mathrm{O}_{2}$, diferindo apenas daqueles que receberam um estresse e permaneceram em $0,6 \mathrm{kPa}$ de $\mathrm{O}_{2}$. Contrariamente aos resultados observados no presente trabalho, WANG \& DILLEY (2000) observaram que a aplicação de ILOS, seguido do armazenamento em $1,5 \mathrm{kPa} \mathrm{de} \mathrm{O}_{2}$, foi eficiente em manter a firmeza de polpa dos frutos. Provavelmente, a concentração de $\mathrm{O}_{2}$ utilizada no presente trabalho, após a aplicação de estresse inicial, tenha sido demasiadamente baixa, de forma a prejudicar a conservação da qualidade dos frutos. Pressões parciais de $\mathrm{O}_{2}$ muito baixas resultam na modificação do metabolismo respiratório celular, iniciando a rota fermentativa. Esta é incapaz de fornecer energia suficiente para reparar danos nas membranas, causados por espécies reativas de oxigênio (VELTMAN et al., 2003), sendo que esses danos ocasionam a perda da compartimentalizacão celular, gerando o extravasamento do seu conteúdo (PEDRESCHI et al., 2009) e, consequentemente, perda da firmeza de polpa. A aplicação de 1-MCP e estresse inicial não influenciaram a porcentagem de frutos sadios.

A degenerescência da polpa e os sólidos solúveis totais não foram alterados pela aplicação do 1-MCP, nem pelas condições de estresse inicial e ultrabaixo oxigênio (dados não apresentados). ZANELLA(2003), testando 1-MCP, estresse inicial com baixo $\mathrm{O}_{2}$ e ultrabaixo $\mathrm{O}_{2}$ em maçãs, também não observou influência desses tratamentos no conteúdo de sólidos solúveis. A acidez titulável não apresentou interação significativa $(\mathrm{P} \geq 0,05)$ entre os fatores $1-\mathrm{MCP}$ e condição de armazenamento (Tabela 2). Essa resposta discorda dos resultados obtidos por FAN et al. (1999) e ZANELLA (2003), que afirmaram que o 1-MCP retardou a degradação de ácidos orgânicos, mantendo 
Tabela 2 - Acidez titulável total (ATT), atividade da enzima ACC oxidase, produção de etileno e respiração em maçãs Fuji após oito meses de armazenamento a $-0,5 \pm 0,2^{\circ} \mathrm{C}$ (UR $96 \pm 1 \%$ ) e em atmosfera controlada com ultrabaixo oxigênio e estresse inicial por baixo oxigênio com e sem a aplicação de 1 -MCP $\left(1.000 \mathrm{~nL} \mathrm{~L}^{-1}\right)$, mais sete dias a $20 \pm 1^{\circ} \mathrm{C}$ (UR $82 \pm 5 \%$ ).

\begin{tabular}{|c|c|c|c|c|c|c|}
\hline \multirow{2}{*}{ Condição ${ }^{*}$ Estresse $/ \mathrm{kPa}$ de $\mathrm{O}_{2}$} & \multicolumn{6}{|c|}{ 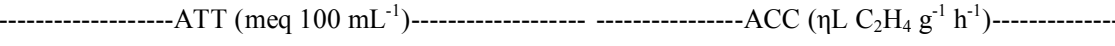 } \\
\hline & Sem 1-MCP & Com 1-MCP & Média & Sem 1-MCP & Com 1-MCP & Média \\
\hline Análise inicial & \multicolumn{3}{|c|}{4,30} & \multicolumn{3}{|c|}{16,38} \\
\hline Sem estresse $/ 1,0$ & 3,38 & 3,63 & $3,50 \mathrm{a}$ & $39,79 \mathrm{Aa}$ & $5,23 \mathrm{Ba}$ & 22,51 \\
\hline 1 estresse $/ 0,8$ & 3,05 & 3,20 & $3,12 \mathrm{bc}$ & $12,78 \mathrm{Ab}$ & $5,14 \mathrm{Ba}$ & 8,96 \\
\hline Sem estresse $/ 0,6$ & 3,25 & 3,33 & $3,29 \mathrm{ab}$ & $15,26 \mathrm{Ab}$ & $1,71 \mathrm{Bb}$ & 8,48 \\
\hline 1 estresse $/ 0,6$ & 3,08 & 2,95 & $3,01 \mathrm{c}$ & $11,99 \mathrm{Ab}$ & $4,96 \mathrm{Ba}$ & 8,47 \\
\hline 2 estresses $/ 0,6$ & 3,08 & 3,08 & $3,07 \mathrm{bc}$ & $18,28 \mathrm{Ab}$ & $5,33 \mathrm{Ba}$ & 11,80 \\
\hline Média & $3,16 \mathrm{~A}$ & $3,23 \mathrm{~A}$ & & 19,62 & 4,47 & \\
\hline \multirow[t]{2}{*}{ CV $(\%)$} & \multicolumn{3}{|c|}{5,45} & \multicolumn{3}{|c|}{12,82} \\
\hline & \multicolumn{3}{|c|}{----Etileno $\left(\mu \mathrm{L} \mathrm{C}_{2} \mathrm{H}_{4} \mathrm{~kg}^{-1} \mathrm{~h}^{-1}\right)-$} & ------Respi & ão $\left(\mathrm{mL} \mathrm{CO}_{2} \mathrm{~kg}\right.$ & )----- \\
\hline Análise inicial & & 0,416 & & \multicolumn{3}{|c|}{6,61} \\
\hline Sem estresse $/ 1,0$ & $0,108 \mathrm{Aa}^{* *}$ & $0,135 \mathrm{Aa}$ & 0,122 & $3,62 \mathrm{Aa}$ & 3,84 Aab & 3,73 \\
\hline 1 estresse $/ 0,8$ & $0,115 \mathrm{Aa}$ & $0,133 \mathrm{Aa}$ & 0,124 & 5,29 Aa & $5,64 \mathrm{Aa}$ & 5,46 \\
\hline Sem estresse $/ 0,6$ & $0,202 \mathrm{Aa}$ & $0,067 \mathrm{Ba}$ & 0,135 & $4,68 \mathrm{Aa}$ & $2,52 \mathrm{Bb}$ & 3,60 \\
\hline 1 estresse $/ 0,6$ & $0,122 \mathrm{Aa}$ & $0,091 \mathrm{Aa}$ & 0,107 & $4,36 \mathrm{Aa}$ & 4,42 Aab & 4,39 \\
\hline 2 estresses $/ 0,6$ & 0,097 Aa & $0,080 \mathrm{Aa}$ & 0,089 & $5,16 \mathrm{Aa}$ & 3,78 Aab & 4,47 \\
\hline Média & 0,129 & 0,101 & & 4,62 & 4,04 & \\
\hline CV (\%) & & 39,4 & & & 20,3 & \\
\hline
\end{tabular}

*Estresse inicial por baixo oxigênio obtido por meio da exposição dos frutos durante 14 dias a uma concentração de $0,2 \mathrm{kPa}$ de $\mathrm{O}_{2}$.

*** Médias seguidas por letras iguais, maiúsculas nas linhas e minúsculas nas colunas, não diferem entre si pelo teste de Tukey, a 5\% de probabilidade de erro.

maior acidez titulável. $\mathrm{O}$ armazenamento a $1,0 \mathrm{kPa}$ de $\mathrm{O}_{2}$ manteve a maior acidez, no entanto não diferiu da condição sem estresse inicial associado a $0,6 \mathrm{kPa}$ de $\mathrm{O}_{2}$. Esses resultados discordam de MATTĖ et al. (2005) que, após três anos de observações em câmaras comercias de armazenamento, com maçãs Red Delicious em ILOS (15 dias a $0,5 \mathrm{kPa}$ de $\mathrm{O}_{2}$ ) seguido de $\operatorname{ULO}(0,9$ a $1 \mathrm{kPa}$ de $\mathrm{O}_{2}$ ), comprovaram maior acidez nestes frutos comparados com aqueles armazenados na mesma condição de AC e sem ILOS.

A aplicação de 1-MCP diminuiu significativamente a atividade da enzima ACC oxidase em todas as condições de armazenamento (Tabela 2). Para os frutos que não receberam aplicação de 1-MCP, o armazenamento em $1 \mathrm{kPa}$ de $\mathrm{O}_{2}$ e sem estresse inicial proporcionou a maior atividade da enzima. Esse resultado indica que houve influência das condições de estresse e armazenamento em baixo $\mathrm{O}_{2}(0,6$ e $0,8 \mathrm{kPa})$ sobre a atividade da enzima ACC oxidase. Essa enzima necessita da presença de $\mathrm{O}_{2}$ para converter a ACC (Ácido 1-aminociclopropano-1-carboxilico) em etileno (YANG \& HOFFMAN, 1984). Além disso, o baixo $\mathrm{O}_{2}$ $\left(0,6 \mathrm{kPa}\right.$ de $\left.\mathrm{O}_{2}\right)$ pode ter proporcionado a produção de compostos fermentativos, como acetaldeído e etanol, em quantidades capazes de inibir a atividade da ACC oxidase (ASODA et al., 2009).
A aplicação do 1-MCP proporcionou menor atividade da enzima ACC oxidase, porém não foi eficiente em diminuir a produção de etileno (Tabela 2). Dentre os frutos que receberam aplicação de 1-MCP, aqueles armazenados em $0,6 \mathrm{kPa}$ de $\mathrm{O}_{2}$ e sem estresse inicial apresentaram menor atividade da enzima ACC oxidase, refletindo menor produção de etileno. No entanto, todas as condições avaliadas neste trabalho proporcionaram baixa produção de etileno (inferior a $0,2 \mu \mathrm{L} \mathrm{C}_{2} \mathrm{H}_{4} \mathrm{~kg}^{-1} \mathrm{~h}^{-1}$ ), quando comparadas com outros trabalhos, a exemplo de BRACKMANN et al. (2010) que, aplicando pressões parciais de $1,2 \mathrm{kPa}$ de $\mathrm{O}_{2}$ e menor que $0,5 \mathrm{kPa}$ de $\mathrm{CO}_{2}$ (AC estática) em maçãs Fuji, observaram produção de etileno de 4,99 $\mathrm{L} \mathrm{C}_{2} \mathrm{H}_{4} \mathrm{~kg}^{-1} \mathrm{~h}^{-1}$. Dessa forma, pode-se inferir que as condições de armazenamento com estresse inicial e concentração de $\mathrm{O}_{2}$ menores que $1 \mathrm{kPa}$ são eficientes no controle da produção de etileno, mesmo sem a aplicação de 1-MCP.

A respiração dos frutos, quantificada pela produção de $\mathrm{CO}_{2}$, apresentou um comportamento semelhante à produção de etileno, sendo que, com exceção da condição de armazenamento de $0,6 \mathrm{kPa}$ e sem estresse inicial, nos demais tratamentos, não houve efeito positivo da aplicação de 1-MCP na redução da atividade respiratória. 


\section{CONCLUSÃO}

$\mathrm{O}$ armazenamento sem estresse inicial por baixo $\mathrm{O}_{2}$ associado a $1,0 \mathrm{kPa}$ ou $0,6 \mathrm{kPa}$ de $\mathrm{O}_{2}$ foram mais eficientes em manter a qualidade de maçãs Fuji, indicando que o período de 14 dias de estresse inicial com $0,2 \mathrm{kPa}$ de $\mathrm{O}_{2}$ é uma condição muito extrema para esta cultivar. Apesar de manter menor atividade da enzima ACC oxidase, o tratamento dos frutos com 1-MCP não trouxe vantagens adicionais na manutenção da qualidade de maçãs Fuji armazenadas sob as condições ultrabaixas de $\mathrm{O}_{2}$ testadas no presente trabalho.

\section{REFERÊNCIAS}

ARGENTA, L.C. et al. Responses of Fuji apples to short and long duration exposure to high $\mathrm{CO}_{2}$. Postharvest Biology and Technology, v.24, p.13-24, 2002. Disponível em: <http:/ / w w w.sciencedirect.com/science/article/pii/ S092552140100120X>. Acesso em: 24 fev. 2012. doi: 10.1016/S0925-5214(01)00120-X.

ARGENTA, L.C. et al. Factors affecting efficacy of 1-MCP to maintain quality of apples fruit after storage. Acta Horticulturae, v.682, p.1249-1256, 2005.

ASODA, T. et al. Effects of postharvest ethanol vapor treatment on ethylene responsiveness in broccoli. Postharvest Biology and Technology, v.52, p.216-220, 2009. Disponível em: $<$ http:/ /www.sciencedirect.com/science/article/pii/S0925521408002779>. Acesso em: 07 out. 2011. doi: 10.1016/j.postharvbio.2008.09.015.

BLANKENSHIP, S.M.; UNRATH, C.R. Ethylene inhibitor, 1methylcyclopropene, delays apple softening. HortScience, v.33, 469p, 1998 .

BRACKMANN, A. et al. Efeito da temperatura e condições de atmosfera controlada na armazenagem de maçãs Fuji com incidência de pingo-de-mel. Revista Brasileira de Agrociência, v.8, p.37-42, 2002. Disponível em: $<$ http:// www.ufpel.tche.br/faem/agrociencia/v8n1/artigo06.pdf $>$. Acesso em: 07 out. 2011.

BRACKMANN, A. et al. Aplicações pré-colheita de cálcio na qualidade pós-colheita de maçãs Fuji. Ciência Rural, v.40, p.1435-1438, 2010. Disponível em: <http://dx.doi.org/ 10.1590/S0103-84782010000600032>. Acesso em: 12 out. 2011. doi: 10.1590/S0103-84782010000600032.

BUFLER, G. Ethylene-promoted conversion of 1aminocyclopropene-1-carboxylic acid to ethylene in peel of apple at various stages of fruit development. Plant Physiology, v.80, p.539-543, 1986. Disponível em: <http:// www.ncbi.nlm.nih.gov/pmc/articles/PMC1075151/pdf/ plntphys00597-0251.pdf>. Acesso em: 12 out. 2011.

CERETTA, M. et al. Tolerância da maçã Gala a pressões parciais extremas de $\mathrm{O}_{2}$ e $\mathrm{CO}_{2}$ durante o armazenamento. Revista Brasileira de Armazenamento, v.35, p.60-69, 2010.

CORRENT, A.R. et al. Efeito do 1-metilciclopropeno em maçãs Fuji armazenadas em Atmosfera refrigerada e atmosfera controlada. Revista Brasileira de Agrociência, v.11, p.91-
94, 2005. Disponível em: <http://www.ufpel.tche.br/faem/ agrociencia/v11n1/artigo15.pdf>. Acesso em: 22 fev. 2012.

FAN, X.T. et al. 1-methylcyclopropene inhibits apple ripening. Journal of the American Society for Horticultural Science, v.124, n.6, p.690-695, 1999.

KADER, A.A. Postharvest technology of horticultural crops. Oakland: University of California, 2002. 3.v. 580p.

$\mathrm{KE}$, D. et al. Regulation of fermentative metabolism in fruits and vegetables by controlled atmospheres. In: INTERNATIONAL CONTROLLED ATMOSPHERE RESEARCH CONFERENCE, 6., 1993, Ithaca, NY. Proceedings... Ithaca, New York: Postharvest Horticulture Series, 1993. V.1, p.63-67.

MATTÈ, P. et al. ILOS + ULO as a practical technology for apple scald prevention. ActaHorticulturae, v.682, p.15431550,2005

PEDRESCHI, R. et al. Metabolic profiling of 'Conference' pears under low oxygen stress. Postharvest Biology and Technology, v.51, p.123-130, 2009. Disponível em: <http://www.sciencedirect.com/ science/article/pii/S0925521408001713>. Acesso em: 18 out. 2011. doi: $10.1016 /$ j.postharvbio.2008.05.019

VALDEBENITO SANHUEZA, R.M. et al. Características e controle da podridão “olho de boi” nas maçãs do Sul do Brasil. Bento Gonçalves: EMBRAPA-CNPUV, 2006. 12p. (Circular Técnica, 66).

VELTMAN, R.H. et al. Internal browning in pear fruit (Pyruscommunis L. cv 'Conference') may be a result of a limited availability of energy and antioxidants. Postharvest Biology and Technology, v.28, p.295-302, 2003. Disponível em: $<$ http:// www.sciencedirect.com/science/article/pii/S0925521402001989>. Acesso em: 18 out. 2011. doi: 10.1016/S0925-5214(02)00198-9.

WANG, Z.; DILLEY, D.R. Initial low oxygen stress controls superficial scald of apples. Postharvest Biology and Technology, v.18, p.201-213, 2000. Disponível em: <http:// ww w.sciencedirect.com/science/article/pi i/ S0925521402001989>. Acesso em: 18 out. 2011. doi: 10.1016/ S0925-5214(00)00067-3.

WATKINS, C.B. et al. Responses of early, mid and late season apple cultivars to postharvest application of 1-methylciclopropene (1-MCP) under air and controlled atmosphere storage conditions. Postharvest Biology and Technology, v.19, n.1, p.17-32, 2000. Disponível em: <http://www.sciencedirect.com/science/article/pii/ S0925521400000703>. Acesso em: 18 out. 2011. doi:10.1016/ S0925-5214(00)00070-3.

YANG S.F.; HOFFMAN, N.E. Ethylene biosynthesis and its regulation in higher plants. Annual Review of Plant Physiology, v.35, p.155-189, 1984. Disponível em: <http://www.annualreviews.org/ doi/pdf/10.1146/annurev.pp.35.060184.001103>. Acesso em: 18 out. 2011. doi: 10.1016/S0925-5214(00)00067-3

ZANELLA, A. Control of apple superficial scald and ripening - a comparison between 1-methylcyclopropene and diphenylamine postharvest treatments, initial low oxygen stress and ultra low oxygen storage. Postharvest Biology and Technology, Amsterdam, v.27, n.1, p.69-78, 2003. Disponível em: $<\mathrm{http}$ :/www.sciencedirect.com/ science/article/pii/S0925521402001874>. Acesso em: 18 out. 2011. doi: 10.1016/S0925-5214(02)00187-4. 